\title{
Análise Crítica de uma Revista Institucional: as Memórias do Instituto Oswaldo Cruz ${ }^{1}$
}

\section{A Critical Appraisal of an Institutional Journal: Memórias do Instituto Oswaldo Cruz}

\section{Antonio Agenor Briquet de Lemos²}

BRIQUET DE LEMOS, A. A. A Critical Appraisal of an Institutional Journal: Memórias do Instituto Oswaldo Cruz. Cad. Saúde Públ., Rio de Janeiro, 9 (2): 161-169, Apr/Jun, 1993.

The journal Memórias do Instituto Oswaldo Cruz, founded and maintained over the course of many years for the exclusive publication of research results from one single institution, has undergone changes over the last decade which have resulted in an open journal. Conditions leading to the journal's founding and the excellent role it has played in the dissemination of knowledge produced by the Instituto Oswaldo Cruz are examined. The fact that it has differed from journals published by scientific societies does not diminish its importance. The present option to give this journal an international slant, with possibilities for competing on the foreign market, and which would be facilitated by the preference given to papers written in English, raises some questions about the role of Brazilian specialized journals within the framework of our scientific development.

Key words: Periodicals; Academies and Institutes; Tropical Medicine

\section{INTRODUÇÃO}

Um esclarecimento sobre o conceito de revista institucional torna-se necessário ao iniciarmos este trabalho. Em princípio, as revistas são institucionais, com exceção daquelas que representam a iniciativa de um ou mais de um indívíduo, fora da égide de uma organização. Institucionais no sentido que, sociologicamente falando, tanto uma sociedade científica quanto uma universidade, uma faculdade isolada, uma empresa comercial ou um clube de futebol são instituições.

Como, no entanto, o uso da expressão "revista institucional" parece ter assumido, no meio editorial, o significado específico de uma publicação periódica estrita e exclusivamente vinculada aos interesses e objetivos de uma determi-

${ }^{1}$ Versão modificada do trabalho apresentado no I Seminário sobre Editoração de Revistas Editadas no Estado de São Paulo, Campinas, SP, Novembro de 1991. ${ }^{2}$ SHIN - QL 3 - Conjunto 8-Casa 19, Brasília, DF, 71505-285, Brasil. nada organização, aceitaremos esta acepção restritiva no curso deste trabalho. Antes, porém, queremos registrar a tipologia consignada por Lambert (1985) para as publicações periódicas do ponto de vista de seus publicadores (editores), sem considerar, portanto, sua diversificação segundo seus objetivos. Assim, no que concerne às organizações envolvidas na edição de revistas, temos as que são publicadas por a) associações científicas e organizações profissionais; b) editoras comerciais; c) organizações sem fins lucrativos; d) estabelecimentos de ensino; e, finalmente, e) instituições governamentais e de pesquisa.

A revista que é objeto deste trabalho incluise, portanto, no grupo e, ou seja, aquelas que são editadas por instituições governamentais e de pesquisa.

\section{ORIGENS DAS MEMÓRIAS}

Sem procurar forçar a aceitação da idéia de que Oswaldo Cruz teria copiado, na organização do Instituto de Soroterapia, o modelo do 
Instituto Pasteur, de Paris, onde ele fez sua "pós-graduação", o que já foi analisado por Stepan (1976) e Benchimol (1990), não se pode excluir a possibilidade de que este centro de pesquisas francês ofereceu a Oswaldo Cruz a oportunidade de vivências e experiências que ele iria adaptar e adotar na instituição cuja direção lhe estava sendo confiada.

Dentre aquilo que viu no Instituto Pasteur, certamente o impressionou a existência de uma revista própria, os Annales de l'Institut Pasteur, fundada em 1887. A iniciativa de editá-la dever-se-ia ao fato de a "revista oficial da Académie des Sciences ser um veículo formal demais para noticiar as pesquisas do Instituto", segundo a já citada Nancy Stepan (1976). Efetivamente, os Annales, como informa Kourilsky (1989), foram lançados um ano antes da inauguração do Instituto Pasteur.

No decreto $\mathrm{n}^{\mathrm{o}} 1.812$, baixado pelo Congresso Nacional e sancionado pelo presidente da República, em 12 de dezembro de 1907, que criou o Instituto de Patologia Experimental de Manguinhos, ficava determinado, conforme transcrevem Barbosa \& Resende (1909), que "os estudos procedidos no Instituto de Manguinhos serão publicados, a título de Memórias, ao passo que se forem confirmando as experiências. As Memórias serão distribuídas pelas escolas profissionais, de medicina, de veterinária e de agricultura, existentes no país, constituindo objeto de permuta com as publicações estrangeiras do mesmo gênero" (artigo $1^{\circ}$, parágrafo $9^{\circ}$ ).

Seriam as revistas então existentes no país inadequadas para veicular os resultados das pesquisas realizadas no novo Instituto? É provável que sim. As tentativas feitas até então para editar revistas científicas não tinham sido muito auspiciosas. As poucas que tinham sobrevivido levavam uma existência precária. $\mathrm{Na}$ área médica, destacava-se a revista Brasil-Médico (1887-1971), fundada por Antônio Augusto de Azevedo Sodré (1864-1929), provavelmente como iniciativa individual e com recursos próprios. Ele, além de médico e professor, foi deputado federal e prefeito do então Distrito Federal.

No Brasil-Médico vários pesquisadores de Manguinhos publicaram trabalhos, tanto antes quanto depois da fundação das Memórias, inclusive Carlos Chagas, que ali veiculou sua nota prévia sobre a tripanossomíase americana. Os 60 trabalhos de Carlos Chagas publicados em revistas estão distribuídos da seguinte forma: $1^{\circ}$ ) Brasil-Médico, com 17 artigos; $2^{\circ}$ ) Memórias, com 10 artigos; $3^{\circ}$ ) Bulletin de la Société de Pathologie Exotique e Comptes Rendus de la Société de Biologie, com três artigos cada uma. Quinze artigos foram publicados em 14 outras revistas estrangeiras e os restantes 12 artigos apareceram em igual número de revistas nacionais (Carlos, 1959).

Havia carência de canais apropriados à publicação de trabalhos científicos. Durante anos, conforme assinala Neiva (1922), sobretudo no campo da história natural, contribuições de valor tinham sido publicadas em jornais diários. Ao se percorrer a bibliografia de Adolfo Lutz, compilada por Neiva (1941), constata-se que ele chegou a publicar até no Diário Oficial do Pará.

No primeiro decênio do século XX, surgiram outras revistas que poderiam ser utilizadas pelos pesquisadores de Manguinhos, e algumas efetivamente o foram, como a Revista da Sociedade Scientifica de São Paulo (1905-1913) e a Revista Médica de São Paulo (1889-1914), entre outras. Nenhuma dessas publicações poderia, porém, arcar com o tipo de artigo, em geral minucioso e extenso, além de bilíngüe, que as Memórias iriam publicar. Com sua característica de registro permanente das pesquisas realizadas no Instituto, a revista de Manguinhos, até a década de 1960, publicava textos que, pela sua extensão, não seriam aceitos em revistas dedicadas a artigos redigidos com as dimensões habituais. Um desses últimos trabalhos, por exemplo, foi a completíssima monografia sobre trematódeos do Brasil, com 886 páginas e 557 figuras, de Lauro Travassos, publicada em 1969.

No primeiro regulamento do Instituto, estabelecia-se que a "impressão das Memórias poderá ser feita onde maiores vantagens houver para que a realização dos trabalhos que elas encerrarem seja a mais perfeita possível". Dificilmente esta exigência seria atendida pelas revistas existentes na época. 


\section{OSWALDO CRUZ E AS MEMÓRIAS}

Embora Aragão (1950) afirme que Oswaldo Cruz, "em fins de 1908", tinha resolvido editar as Memórias, o fato é que, como vimos, no decreto de 1907, estava consignada a responsabilidade de o Instituto publicar sua revista. Mas este depoimento de Aragão esclarece que: "Como não houvesse, na época, no Instituto, quem pudesse cuidar do assunto [a implantação da revista], ele [Oswaldo Cruz] tomou a si todo o trabalho, desde a escolha das máquinas impressoras, seleção dos tipos, encomenda do papel, entendimentos com litógrafos e especialistas na feitura de clichês, a seleção dos tradutores para os artigos e, finalmente, ainda a revisão das provas, sem demonstrar, como de costume, o menor enfado por todo o labor rotineiro que tomara a si."

E continua o mesmo Aragão: "Graças ao seu dedicado esforço, em abril de 1909 apareceu o primeiro fascículo das Memórias do Instituto Oswaldo Cruz, muito bem impresso, tendo cada artigo um texto em português e outro em francês, inglês ou alemão, à vontade do autor, para tornar o assunto acessível aos leitores estrangeiros desconhecedores do nosso idioma. [...] Durante muito tempo encarregou-se Oswaldo dos trabalhos relativos à publicação das Memórias, esmerando-se para que saíssem perfeitas, e unicamente quando tinha de ausentar-se passava a tarefa a Lutz, que a executava com muito zelo e boa vontade."

Apesar de somente em 1927 aparecer no fascículo 1 do volume 20 um colofão indicando que o local de impressão era a "Typographia do Instituto Oswaldo Cruz - Rio de Janeiro Brasil", podemos acreditar, pelo testemunho de Beaurepaire Aragão, que essa foi a oficina que imprimiu a revista desde seu início até 1940 . Em 1941, a impressão passou a ser feita na Imprensa Nacional, que, pelo seu regimento de 16 de julho de 1940 (decreto $n^{\circ} 5.963$ ), tornarase responsável pela execução de todos os trabalhos gráficos das repartições federais. Com isso, foram extintas as oficinas gráficas dessas repartições.

Ao montar sua própria tipografia, o Instituto certamente procurava atender ao critério de qualidade exigido pelo seu regulamento. $\mathrm{O}$ envolvimento pessoal de Oswaldo Cruz na edição das Memórias respaldava-se também no regulamento, o qual determinava que só poderiam ser publicados com o nome e responsabilidade do Instituto os trabalhos que fossem aprovados pelo diretor. Entre as competências deste estava a de "autorizar a publicação dos trabalhos científicos" (artigos 17 e 21 alínea m), como se lê em Barbosa \& Resende (1909).

Em depoimento sobre a personalidade de Oswaldo Cruz, Ezequiel Dias (1922), que foi um de seus colaboradores mais próximos, afirma que ele talvez revisasse os artigos. Os "estudos assim elaborados recebiam a sua influência benéfica, embora muitas vezes o assunto não lhe fosse da especialidade. É que ninguém como ele sabia entrever as causas de erro, as aparências enganosas, as conclusões ilógicas".

Ao contrário do que acontece hoje em dia com revistas "institucionais" de caráter pouco sério, Oswaldo Cruz jamais se valeu das páginas do periódico que fundou e dirigiu para se autopromover, nem mesmo assinando artigos na categoria de "colaborador". Ouçamos de novo o depoimento de Ezequiel Dias: “[...] esse homem extraordinário, assim que conseguiu a primeira turma de discípulos suficientemente versados em assuntos de laboratório, tratou de fundar uma revista magnífica; mas desde esse dia nunca mais veio à luz um trabalho original firmado por seu nome".

\section{DO FECHAMENTO À ABERTURA}

As Memórias eram, portanto, uma revista tipicamente "institucional", no sentido que desempenhavam o papel de arquivo da produção científica da instituição que a editava. Era uma publicação fechada à colaboração externa, a não ser quando se tratava de trabalhos realizados com a colaboração de pesquisadores de outra instituição. Assim é que, em 1923, surge, logo após o sumário, a seguinte informação: “As Memórias, órgão oficial do Instituto Oswaldo Cruz, são reservadas exclusivamente à publicação de trabalhos originais nele realizados."

Esta informação é repetida textualmente em todos os fascículos até 1956, quando o advérbio "exclusivamente" é substituído por "precipua- 
mente". Três anos depois, em 1959, há nova mudança no conteúdo desta informação, a qual passa a explicitar que a revista é "destinada à divulgação de trabalhos de pesquisa original elaborados por membros do corpo científico do Instituto Oswaldo Cruz, excepcionalmente [grifo nosso] incluindo colaboração de autores estranhos à instituição". Esta advertência deixa de aparecer com o número 3/4 do volume 74 , em 1976. A partir de 1980, no editorial que inaugura sua nova fase, seu editor de então, Coura (1980), esclarece que as Memórias "abrem as suas páginas para publicação de trabalhos de outras instituições nacionais e estrangeiras com a condição de que sejam originais e de bom nível, dentro das suas normas de publicação".

\section{A PREFERÊNCIA PELO INGLÊS}

Na fase que podemos chamar "novíssima", iniciada em 1989, implantam-se mudanças na política geral, passando a revista a contar com a colaboração de editores associados em diferentes áreas do conhecimento científico, com o objetivo, segundo Garcia (1989), de "tornar mais dinâmica a escolha dos conselheiros e estimular a apresentação de artigos e revisões de alta qualidade científica", de preferência em inglês, ficando a apresentação de originais em português na dependência de prévia anuência do editor.

Compare-se esta mudança com o que determinava o regulamento do decreto de 1907, o qual estipulava que os trabalhos a serem publicados poderiam ser escritos "em diversas línguas, mas deles haverá sempre uma edição em português" (Barbosa \& Resende, 1909).

A preferência dada ao inglês volta a aproximar Manguinhos de seu congênere francês. Também em 1989, os Annales de l'Institut Pasteur, reputados "o farol internacional da pesquisa francesa”, mudavam seu próprio título, além do conteúdo, para o inglês, nas três seções em que já se havia subdividido, para Research in Microbiology, Research in Virology, e Research in Immunology. Uma mudança também significativa, ocorrida poucos anos antes, foi a associação do Institut Pasteur com o grupo editorial Elsevier, uma das maiores empresas do mundo no campo da editoração científica e técnica, que passou a editar os antigos Annales.

Por essa época, mesmo antes de adotar o título em inglês, abrindo mão daquele que marcava claramente sua origem e vinculação institucional, já se verificava que, embora quase $58 \%$ dos artigos publicados fossem originários de países francófonos, $84 \%$ desses artigos eram redigidos em inglês. Num país tão cioso de seu idioma, particularmente pela função de língua franca internacional que o francês desempenhou nos campos científico, literário e diplomático, durante muitos anos, este fato alcançou certa repercussão, a ponto de merecer uma reportagem numa revista de grande circulação (Castello, 1989).

No editorial de lançamento da Research in Microbiology, seu redator-chefe alegou que "todas as revistas devem agora encontrar suas raízes na comunidade internacional em geral e interagir com uma ampla rede de cientistas e instituições" (Kourilsky, 1989).

\section{QUEM PUBLICA NAS MEMÓRIAS}

Em 1989, a editora administrativa das Memórias do Instituto Oswaldo Cruz apresentou dados adicionais relativos à história desta revista e algumas informações sobre as características dos trabalhos publicados no período 1980-1988. Os textos oriundos do próprio Instituto Oswaldo Cruz corresponderam a 61,9\% (351) de um total de 567 artigos publicados no período. Outras instituições nacionais contribuíram com 26,4\% (150 artigos), e de instituições estrangeiras vieram 66 artigos $(11,7 \%), 49$ dos quais procediam de países da América Latina (Willcox, 1989).

Atualizando esses dados, verificamos que, durante os anos de 1989 e 1990, foi publicado um total de 190 artigos, dos quais 38 (20\%) haviam sido produzidos exclusivamente no Instituto Oswaldo Cruz. Artigos que resultaram da colaboração entre pesquisadores do Instituto com os de outras instituições, brasileiras ou estrangeiras, somaram 58 (30,8\%). A participação de trabalhos de pessoas estranhas à instituição totalizou, nesses dois anos, 94 artigos, ou seja, quase a metade $(49,47 \%)$ do total de artigos publicados. A comparação destes 
dados com os do trabalho de Willcox deve ser feita com cautela, pois não sabemos se o que ela contou como trabalhos "produzidos na própria instituição" inclui aquilo que separamos como trabalhos feitos em colaboração entre pesquisadores do Instituto e de outras instituições nacionais ou estrangeiras.

No período de 1989-1990, foram publicados 44 trabalhos de autores de instituições estrangeiras, ou seja, $23,15 \%$ do total, número percentualmente significativo, tanto para esses dois anos quanto em comparação com o período de 1980 a 1988.

Ainda que seja proeminente a participação de trabalhos oriundos da própria organização que edita a revista, verifica-se o fato inquestionável de que ela tende a se caracterizar por um certo equilíbrio entre artigos, digamos, "endógenos" e "exógenos". Em relação a estes últimos, devese salientar a importância que passam a ter alguns países latino-americanos como fontes de artigos publicados. Assim, a revista não somente se torna um veículo de difusão da produção científica nacional, sem limitações de qualquer tipo, como também caminha para justificar o lema que passou a estampar em sua capa a partir de 1987: "An international journal of biological and biomedical research".

\section{AS MUDANÇAS NO MECANISMO DE AVALIAÇÃO DE ORIGINAIS}

A abertura da revista caracteriza-se também pela adoção, formal e sistemática, dos procedimentos de avaliação de originais encaminhados para publicação. Se tudo leva a crer que, durante muitos anos, essa avaliação estava concentrada na pessoa do diretor do Instituto, hoje em dia o processo de avaliação é amplo, envolvendo um conselho editorial de notáveis e a colaboração de consultores e especialistas.

A evolução histórica desse processo mostra que somente em 1942 surgiu a figura de um diretor-responsável. Em 1947, passou a haver dois responsáveis. Em 1959, a revista mencionava um "redator-secretário das publicações". Em 1964, apareceu, em seu lugar, a seguinte indicação de responsabilidade: "Setor de Publicações e Divulgação". Em 1965, passou a ser citada uma "comissão de redação das publi- cações" formada por três pesquisadores, número que baixou para dois em 1968, voltou a ser de três em 1970, e passou para cinco em 1975. Em 1976, desapareceram os nomes das autoridades do Instituto e até mesmo os da comissão de publicações e, em seu lugar, registrou-se "número revisado pela Assessoria Editorial das Memórias do Instituto Oswaldo Cruz em 1979". $\mathrm{Na}$ fase iniciada em 1980, aparece "um novo Conselho Editorial, em nível nacional", nas palavras de Coura (1980).

\section{CONSIDERAÇÕES FINAIS}

Uma das instituições que mais refletem, no começo do século XX, a virada histórica representada pelo primeiro esforço significativo de modernização do país é o Instituto Oswaldo Cruz. Sua criação e florescimento relacionamse, como causa e efeito, com aquele momento em que a população carioca gabava-se do novo visual de sua cidade e da chegada de novas tecnologias trazidas pelo novo século. Esse orgulho ficou sintetizado na famosa frase: "o Rio civiliza-se", que refletia, entre outros progressos, o saneamento em que Oswaldo Cruz teve papel tão importante. Era essa uma das ocasiões em que se manifestava o sempre recorrente anseio de modernidade, caracterizado então pela crença na capacidade infinita da ciência e da tecnologia, propulsoras do progresso, capazes de superar tudo que antes parecia inalcançável.

No caso do Instituto de Manguinhos, e de acordo com o testemunho de Ezequiel Dias (1922), Oswaldo Cruz "queria o que houvesse de melhor no mundo". Para uma ciência que se tornava cada vez mais complexa, seria inevitável "uma complicação de maquinismos, instalações e pormenores arquitetônicos" [...] em que se "ressalta o uso do ditafone para gravar os protocolos das autopsias, o impressor de endereços para a expedição das Memórias do Instituto Oswaldo Cruz; as Memórias com o seu texto em duas línguas e a riqueza das ilustrações coloridas; [...] a opulência da biblioteca com os seus quatro andares de aço, toda iluminada por dentro, e os seus 40 mil volumes e as suas 1.000 revistas científicas; a sala de leitura, lindamente luxuosa, com as estalactites alvas a 
contrastarem com as admiráveis obras de madeira".

Se as atividades do Instituto já haviam conquistado a Europa com o êxito alcançado por sua participação na XII Conferência Internacional de Higiene, em 1907, em Berlim, suas Memórias também logo seriam reconhecidas no estrangeiro. Uma revista surgida também em 1909, o Bulletin Mensuel de l'Office International d'Hygiène Publique, organismo internacional fundado em 1907 e precursor da Organização Mundial da Saúde, já registrava em seu número de maio de 1910 o artigo de Carlos Chagas sobre a "nova tripanossomíase humana" publicado no fascículo 2 do tomo 1, de agosto de 1909, das Memórias. A repercussão internacional, objetivo sempre buscado tanto por pesquisadores como por instituições científicas e as revistas que estas editam, estava sendo alcançada, como se vê por esse exemplo e pela indexação regular das Memórias em todas as publicações secundárias importantes, de âmbito internacional, publicadas neste século, como o Index Medicus, Biological Abstracts, Excerpta Medica, Tropical Diseases Bulletin e outras.

Indexadas no Science Citation Index a partir de 1969, aí deixaram de ser referenciadas com o número 3 do volume 71, de 1974. Somente quinze anos depois, em 1989, a revista de Manguinhos voltou a ser abrangida por esse índice de citações. Pelos dados nele constantes, artigos publicados nas Memórias foram citados 50 vezes na literatura internacional do ano de 1974, 20 das quais pelas revistas Journal of Immunology (quatro vezes), Transactions of the Royal Society of Tropical Medicine and Hygiene (quatro vezes), Toxicon (quatro vezes), Journal of Parasitology (três vezes), Proceedings of the Helminthological Society of Washington (três vezes) e Bulletin of Entomological Research (duas vezes). As 30 citações restantes ocorreram em 27 outros títulos. Observe-se que 37 (74\%) das citações registradas em 1974 corresponderam a artigos publicados nas Memórias até o ano de 1964, ou seja, dez anos antes da data em que foram editados os artigos citantes (Garfield, 1976).

Com o retorno das Memórias, em 1989, à lista de revistas brasileiras cobertas pelo Science Citation Index, esperamos que os próximos dados a serem divulgados pelo Institute for
Scientific Information abranjam uma série histórica mais representativa, de modo a contribuir para revelar em que medida as alterações introduzidas na revista a partir da década de 1980 ampliaram a sua "citabilidade" internacional.

O nascimento e a sobrevivência das Memórias, como publicação não-vinculada a uma sociedade científica, refletem a especificidade das condições em que se deu o início de nosso desenvolvimento científico. Em outros países, as sociedades científicas tiveram papel proeminente no processo de edição de periódicos especializados que alcançaram êxito e alto índice de sobrevivência, tendo sido mais restrito o papel das instituições governamentais como editoras dessas publicações. O conflito, nesses países, se deu principalmente entre sociedades científicas e editoras comerciais. A origem desse conflito é posterior ao término da Segunda Guerra Mundial, prendendo-se, pelo que se supõe, à participação crescente das editoras comerciais no mercado da edição de revistas científicas após essa época, participação essa ensejada pelo fato de haver então sociedades científicas que somente publicavam em suas revistas artigos de autores que fossem seus membros (Lambert, 1985).

No Brasil, as sociedades científicas sempre levaram uma vida de carências e crises, desde as primeiras tentativas do século XIX, a não ser quando se punham sob a proteção do Estado, como é o caso, por exemplo, do Instituto Histórico e Geográfico Brasileiro, da Imperial Academia de Medicina e tantas outras. Às vezes, nem mesmo o mecenato estatal era suficiente. Por exemplo, os Annaes da Medicina Pernambucana, fundados em 1841 pela Sociedade de Medicina de Pernambuco, com o subsídio de dois contos de réis anuais decretado pela Assembléia Legislativa da província, não conseguiram sobreviver ao terceiro ano, depois de seis números publicados, o último deles ocupado exclusivamente pela polêmica de um autor contra um colega de sociedade (Annaes, 1842-1844).

Como afirmaria Artur Neiva oitenta anos depois, "as sociedades científicas no Brasil, sobretudo aquelas onde predominam médicos, são verdadeiros rinhadeiros" (Neiva, 1922).

As principais revistas científicas que se 
afirmaram na primeira metade deste século ou eram "institucionais" ou dependiam de iniciativas e financiamento de pessoas físicas. No caso das poucas revistas de sociedades surgidas nesse período e que vingaram até nossos dias, temos os atuais Anais da Academia Brasileira de Ciências, que surgiram em 1917, com o título de Revista da Sociedade Brasileira de Ciências, mas cujos primeiros dez anos de vida foram problemáticos. Embora não tenhamos encontrado informação sobre a concessão de subsídios do Estado, constatamos que contou, em seus primeiros três anos, com a possibilidade de ser impressa na Imprensa Nacional e, em 1926, nas Oficinas Tipográficas do Ministério da Agricultura (Paim, 1982).

A publicação de revistas por parte de sociedades científicas vem assumir maior importância somente a partir de meados deste século, mas sempre sujeita às vicissitudes decorrentes das deficiências organizacionais e da falta de recursos financeiros.

A partir de um determinado momento, por motivos que merecem ser investigados, passouse a fazer um prejulgamento do valor das revistas ditas institucionais. Pelo seu caráter, em geral, de publicações que se restringiam a publicar a produção científica de determinada organização, e pela ausência (ou ocultação) de mecanismos formais e colegiados de avaliação de originais encaminhados para publicação, começou a se tornar predominante a opinião de que essas revistas fugiam ao paradigma daquilo que se considera saudável em termos de comunicação científica.

Dos cinco pré-requisitos exigidos pelo Programa de Apoio a Revistas Científicas do Conselho Nacional de Desenvolvimento Científico e Tecnológico (CNPq) e da Financiadora de Estudos e Projetos (Finep) para a escolha de publicações a serem financiadas (Oliveira, 1989), as Memórias do Instituto Oswaldo Cruz não atendem, atualmente, apenas ao que recomenda que as revistas sejam, de preferência, mantidas por uma sociedade científica de âmbito nacional. Este pré-requisito, que não exclui a possibilidade de apoio a revistas institucionais, reflete a preocupação de fortalecer as atividades editoriais de organizações abertas que estariam menos sujeitas aos vieses e ao paroquialismo de outros tipos de organizações. Estar-se-ia, assim, induzindo o desenvolvimento da editoração de periódicos científicos conforme os moldes que determinaram a evolução dessas publicações nos principais países desenvolvidos do Ocidente.

Uma das vantagens, pelo menos, de uma revista institucional, no caso brasileiro, é que seu financiamento muitas vezes pode ser garantido no orçamento da instituição de que depende. As revistas de muitas sociedades científicas, ao contrário, devem negociar a obtenção de uma parcela dos recursos (também do Estado) que são distribuídos indiretamente pelas agências de financiamento. Nem mesmo o sucesso de público da revista Ciência Hoje, da Sociedade Brasileira para o Progresso da Ciência, levou-a a se tornar auto-sustentável.

Não há dúvida de que, embora tenha sido, durante a maior parte de sua existência, uma revista "fechada", as Memórias alcançaram excelente reputação nacional e internacional. Acreditamos que isso tenha sido menos a consequiência da eventual obediência a padrões formais de organização editorial e muito mais o resultado lógico da seriedade, da competência e da dedicação de todos os que se envolveram na criação e no desenvolvimento do Instituto Oswaldo Cruz, para não falar do carisma de seu fundador. Em outras palavras, uma revista institucional é tão boa (ou tão ruim) quanto a instituição a que esteja vinculada.

Apesar das crises a que estão sujeitas todas as instituições governamentais, sejam essas crises de origem interna ou externa, como a Revolução de 30 ou o golpe de 64, as Memórias mantiveram um padrão de qualidade e regularidade poucas vezes encontrado em publicações congêneres brasileiras. A coleção do período de 1909 a 1979 constitui uma verdadeira enciclopédia das nosologias genericamente designadas como nossas "grandes endemias" e um repositório ainda valioso dos esforços de sucessivos grupos de pesquisadores para compreendê-las e resolvê-las numa escala social. De suas páginas transborda, nesse período, a preocupação constante em revelar e desvendar nossos problemas de saúde pública. 
O êxito das Memórias reflete o êxito do Instituto, e este, como afirma Nancy Stepan (1976), "em parte foi conseqüência da criação de um sistema interligado, envolvendo ciência básica e aplicada, treinamento e emprego de cientistas, produção e consumo de conhecimentos científicos dentro do Brasil".

Chamamos a atenção para a última parte dessa afirmação - "produção e consumo de conhecimentos científicos dentro do Brasil" que coloca diante de nós o velho problema de ciência nacional versus ciência internacional. $\mathrm{E}$ a questão mais específica de qual é a clientela prioritária de uma revista científica brasileira.

$\mathrm{Na}$ fase posterior a 1980 , as Memórias passam a encarar um novo desafio. Deixando de lado uma maneira "caseira" de fazer revista científica, orientando-se para um mercado internacional de consumidores de informação, sua avaliação tenderá a ser feita muito mais em função do impacto que causar nesse mercado do que de seu papel dentro das fronteiras nacionais.

A opção por uma revista que não usa como língua de comunicação o idioma oficial do país (o português, segundo determina o artigo $13 \mathrm{da}$ Constituição federal), opção que não é exclusiva das Memórias, talvez revele, como no caso do Instituto Pasteur, de Paris, que a preocupação está mais em buscar raízes na comunidade internacional do que em criar um sólido mercado interno de consumidores da produção científica que é aqui gerada.

Em relação com esse ponto, tem-se a questão complementar da evasão de artigos de autores brasileiros para revistas estrangeiras. Na opinião de Lancaster (1991), os cientistas brasileiros preferem publicar em inglês e não em português, "porque as revistas de língua inglesa são consideradas mais prestigiosas e porque muitos desses cientistas estudaram fora do Brasil". E continua este especialista, que tem conhecimento direto de nossa realidade: "Isso cria uma situação um tanto anômala em que os resultados das pesquisas brasileiras são mais acessíveis no exterior do que no próprio país. O fortalecimento das revistas nacionais, associado a um aumento de qualidade do ensino superior, principalmente em nível doutoral (acarretando mais ensino de pós-graduação em âmbito nacional e menos no exterior), poderá resultar num aumen- to da publicação em revistas nacionais e uma diminuição da publicação em outros lugares."

Sabemos que este zelo pela língua nacional pode exalar um ranço de conservadorismo e parecer um xenofobismo anacrônico em tempos ditos pós-modernos, neoliberais e de abertura para o mundo. Vale a pena, porém, lembrar, como o fizeram Giambiagi \& Giambiagi (1983), que a opção por uma língua diferente da língua nacional para a comunicação de conhecimentos científicos "deve responder a motivações culturais e não refletir uma hegemonia política e econômica" e que, por exemplo, no caso da França pelo menos, "o abandono da língua francesa traduz uma mudança na maneira de pesquisar, nos problemas estudados e uma adaptação a padrões e modas que provêm fundamentalmente dos Estados Unidos".

\section{RESUMO}

\section{BRIQUET DE LEMOS, A. A. Análise}

Crítica de uma Revista Institucional: as Memórias do Instituto Oswaldo Cruz. Cad. Saúde Públ., Rio de Janeiro, 9 (2): 161-169, abr/jun, 1993.

Criadas e mantidas durante muitos anos para difundir exclusivamente os resultados de pesquisas de uma instituição, as Memórias do Instituto Oswaldo Cruz vêm passando, desde a década de 1980, por mudanças que as transformaram numa revista aberta. São analisadas as condições em que se deu seu surgimento e o excelente papel que desempenharam na difusão dos conhecimentos produzidos pelo Instituto Oswaldo Cruz. O fato de ter sido uma revista diferente das editadas por sociedades científicas não diminui sua importância. A opção atual, que procura dar à revista uma inclinação internacional, com possibilidades de competir no mercado estrangeiro, para o que contribuiria a preferência dada a artigos escritos em inglês, suscita questionamentos quanto ao papel dos periódicos especializados brasileiros no quadro de nosso desenvolvimento científico.

Palavras-Chave: Periódicos; Academias e Institutos; Medicina Tropical 


\section{REFERÊNCIAS BIBLIOGRÁFICAS}

ANNAES DA MEDICINA PERNAMBUCANA (1842-1844), 1977. Estudo introdutório do Prof. Leduar de Assis Rocha. Recife: Secretaria de Educação e Cultura.

ARAGÃO, H. B., 1950. Notícia histórica sobre a fundação do Instituto Oswaldo Cruz. Memórias do Instituto Oswaldo Cruz, 48: 1-50.

, 1953. Carlos Chagas, diretor de Manguinhos. Memórias do Instituto Oswaldo Cruz, 51: 1-10.

BARBOSA, P. \& RESENDE, C. B., 1909. Os Serviços de Saúde Pública no Brasil Especialmente na Cidade do Rio de Janeiro de 1808 a 1907 (esboço histórico e legislação). Volume 1, Rio de Janeiro: Imprensa Nacional.

BENCHIMOL, J. L. (Org.), 1990. M anguinhos do Sonho à Vida; a Ciência na Belle Époque. Rio de Janeiro: Casa de Oswaldo Cruz-Fiocruz.

CARLOS CHAGAS, 1959. Carlos Chagas (18791934), bio-bibliografia. Rio de Janeiro: Instituto Oswaldo Cruz. (Também in: Coletânea de Trabalhos Científicos (Carlos Chagas), pp. 769780, Brasília: Ed. Universidade de Brasília.)

CASTELlO, M., 1989. Société Institut Pasteur: le virus anglophone. Jours de France, (1790): 19-21, 24.

COURA, J. R., 1980. Editorial. M emórias do Instituto Oswaldo Cruz, 75: 5. , 1987. Memória das M emórias. M emórias do Instituto Oswaldo Cruz, 82:151-153.

DIAS, E., 1922. Traços de Oswaldo Cruz. M emórias do Instituto Oswaldo Cruz, 15: 5-57.

GARCIA, E. S., 1989. Editorial. M emórias do Instituto Oswaldo Cruz, 84: 141.

GARFIELD, E. (Org.), 1976. Journal Citation Reports; a Bibliometric Analysis of References Processed for the 1974 Science Citation Index. Philadelphia: Institute for Scientific Information. (Science Citation Index, 1975 Annual, v. 9.)
GIAMBIAGI, M. S. \& GIAMBIAGI, M., 1983. Sobre a produção científica, a indústria dos papers e outras histórias. Ciência e Cultura, 35: 1442-1451.

KOURILSKY, P., 1989. Editorial. Research in Immunology, 140: 5.

LAMBERT, J., 1985. Scientific and Technical Journals. London: Clive Bingley.

LANCASTER, F. W., 1991. Indexing and A bstracting in Theory and Practice. London: Library Association.

NEIVA, A., 1929. Esboço Histórico sobre a Botânica e Zoologia no Brasil; de Gabriel Soares de Souza, 1587, a 7 de setembro de 1922. São Paulo: Socidade Impressora Paulista. ( $2^{\mathrm{a}}$ ed., Brasília: Universidade de Brasília, 1989.) , 1941. Adolpho Lutz 1855-1940. Memórias do Instituto Oswaldo Cruz, 36: i-ix.

OLIVEIRA, E. C. P., 1989. 0 A poio Governamental às Publicações Periódicas Científicas: o Programa de Apoio a Revistas Científicas do CNPq e da FINEP. Tese de Mestrado, Rio de Janeiro: Escola de Comunicação, Universidade Federal do Rio de Janeiro.

PAIM, A. 1982. Por uma universidade no Rio de Janeiro. In: Universidades e Instituições Científicas no Rio de Janeiro (S. Schwartzman, org.), pp. 17-96, Brasília: Conselho Nacional de Desenvolvimento Científico e Tecnológico.

STEPAN, N., 1976. Gênese e Evolução da Ciência Brasileira; Oswaldo Cruz e a Política de Investigação Científica e M édica. Rio de Janeiro: Artenova-Fundação Oswaldo Cruz.

WILlCOX, M. C., 1989. Memórias do Instituto Oswaldo Cruz: 80 anos de editoração. Memórias do Instituto Oswaldo Cruz, 84: 435-439. 